\section{Transplante de ilhotas na prática clínica: estado atual e perspectivas}

\author{
Islet transplantation as a clinical tool: present state and future perspectives
}

Freddy Goldberg Eliaschewitz',2,3,4, Denise Reis Franco ${ }^{1,2,4}$, Thiago Rennó Mares-Guia', Irene L. Noronha ${ }^{1,5}$, Leticia Labriola', Mari Cleide Sogayar ${ }^{1,6}$

\section{RESUMO}

O transplante de ilhotas é um procedimento em desenvolvimento, como alternativa para o tratamento do diabetes tipo 1 que está na fronteira entre o experimental e o clínico. É uma terapia celular na qual as células são implantadas em território diferente do fisiológico em que apenas determinado número incerto conseguirá se adaptar. Aperfeiçoar este processo para obter os mesmos resultados que no transplante de pâncreas, representa um desafio para o qual convergem contribuições da biologia celular, da imunologia e das técnicas de laboratório que se entrelaçam de maneira extremamente complexa. Este trabalho revisa a literatura expondo a evolução do procedimento, a sua metodologia atual e os resultados clínicos obtidos. As perspectivas futuras do transplante diante dos recentes avanços também são discutidas. Arq Bras Endocrinol Metab. 2009;53(1):15-23.

Descritores

Diabetes hiperlábil; transplante de ilhotas; terapia celular; diabetes tipo 1; imunossupressão.

\begin{abstract}
Islet transplant is an innovative treatment for type 1 diabetic patients, which still lies between experimental and approved transplant therapy. Islet cells are seeded in a non-physiological territory where an uncertain fraction will be able to adapt and survive. Thus, the challenge lies in improving the whole procedure, employing the tools of cell biology, immunology and laboratory techniques, in order to reach the results obtained with whole organ transplant. This review describes the procedure, its progress to the present methodology and clinical results obtained. Future perspectives of islet transplantation in the light of recent biotechnological advances are also focused. Arq Bras Endocrinol Metab. 2009;53(1):15-23.
\end{abstract}

Keywords

Brittle diabetes; islet transplantation; cell therapy; type 1 diabetes; immunosupression

\author{
' Núcleo de Terapia Celular e \\ Molecular (NUCEL), Universidade \\ de São Paulo (USP) \\ ${ }^{2}$ Centro de Pesquisa \\ Clínica (CPClin) \\ ${ }^{3}$ Hospital Heliópolis \\ ${ }^{4}$ Centro de Pesquisa Médica, \\ Notre-Dame Intermédica \\ Sistema de Saúde \\ ${ }^{5}$ Departamento de Clínica \\ Médica, Faculdade de \\ Medicina, USP \\ ' Departamento de Bioquímica, \\ Instituto de Química, USP; \\ São Paulo, SP, Brasil
}

Correspondência para:

Freddy Goldberg Eliaschewitz

Rua Goiás, 91

01244-030 São Paulo SP

freddy.g@uol.com.br

Recebido em 14/Jul/2008

Aceito em 19/Nov/2008

\section{INTRODUÇÃO}

$\mathrm{O}$ diabetes melito tipo l (DMl) é o resultado da destruição autoimune das células-beta pancreáticas, responsáveis pela produção da insulina. Ao longo da história representou uma condição clínica fatal que, com o advento da terapia com insulina exógena, há cerca de 80 anos, se transformou em doença crônica. Até hoje, a insulinoterapia constitui o principal pilar do tratamento destes pacientes ( 1 ) .

O Diabetic Control and Complication Trial (DCCT) (2) demonstrou, de modo inequívoco, que o controle estrito da glicemia é importante para evitar ou retardar as complicações microvasculares, razão pela qual a insulinoterapia deve ser utilizada na sua modalidade intensiva, ou seja, a insulina basal (uma ou mais aplicações diárias) associada à insulina de ação rápida antes das refeições, em doses variáveis de acordo com o conteúdo de carboidratos a serem ingeridos e com o resultado da monitorização dos níveis da glicemia. Novas estratégias para obter um perfil farmacocinético mais fisiológico da insulina administrada com o uso dos análogos da insulina, das insulinas inaláveis e das bombas de infusão contínua têm se tornado disponíveis na última década como alternativas para atingir as metas de controle glicêmico. No entanto, apesar desta 
evolução significativa da insulinoterapia, há pequeno contingente de pacientes (em torno de $5 \%$ a $10 \%$ ) que apresenta flutuações intensas e inesperadas das suas glicemias, resultando múltiplos episódios de hipoglicemia, freqüentemente assintomáticos. Para estes pacientes, o transplante de pâncreas é a alternativa que já está em uso clínico e o transplante de ilhotas (Tx de ilhotas) é a alternativa em desenvolvimento (1).

O racional para o desenvolvimento do Tx de ilhotas é que estas representam apenas $1 \%$ a $2 \%$ da massa celular do pâncreas, sendo todo o restante do órgão representado por tecido não-endócrino, desnecessário para o paciente com DMl.

\section{A EVOLUÇÃO DO TRANSPLANTE DE ILHOTAS}

A primeira tentativa de transplantar ilhotas, ainda que de maneira rudimentar, ocorreu em 1894, portanto, antes que a insulina fosse isolada por Banting, Best e Collip em 1921. Naquela época já se sabia que extratos de pâncreas continham algum elemento capaz de diminuir a glicemia e o Dr. W. Williams tentou implantar pequenos fragmentos de pâncreas ovino no subcutâneo de um rapaz de 15 anos em cetoacidose. Naquela época, os imunossupressores e as conseqüências de um xenotransplante eram completamente desconhecidos e o enxerto foi prontamente rejeitado (1). A história moderna do Tx de ilhotas se inicia bem mais tarde, em 1972, quando P. Lacey conseguiu, pela primeira vez, reverter o diabetes em roedores com um implante de ilhotas (1). Não obstante grande repercussão deste trabalho experimental, época em se imaginou que este procedimento entraria rapidamente para o ensaio clínico, foi apenas em 1990 que Scharp e cols. reportaram ter obtido a insulino-independência em um paciente portador de DMl pelo prazo de um mês (1). As grandes dificuldades técnicas envolvidas no processo laboratorial de isolamento das ilhotas impediram que este experimento fosse replicado em grande escala. Durante a década seguinte, cerca de 450 tentativas de realizar o Tx de ilhotas foram feitas, com índice de sucesso em obter a insulino-independência, pelo prazo mínimo de um mês, de apenas $8 \%$ em pacientes com DMl. Resultados de até $50 \%$ de sucesso foram reportados, quando os pacientes tinham-se tornado diabéticos por terem sido submetidos à pancreatectomia.

No ano de 2000, Shapiro e cols. (3) publicaram dados de uma série de Tx de ilhotas em sete pacientes consecutivos em que todos alcançaram a insulino-independência, pelo período de seguimento de um ano, utilizando um protocolo modificado que viria a ser conhecido como o protocolo de Edmonton. As modificações propostas incluíam: a seleção de pacientes com a função renal preservada, o uso de um novo esquema de imunossupressão sem esteróides, o preparo das ilhotas sem a adição de proteínas xenogênicas e a realização de um implante de grande número de ilhotas, ou seja, de no mínimo, 10.000 IEQs $/ \mathrm{kg}$ do receptor, obtidas de dois a três pâncreas e implantadas em duas infusões. Desde então, mais de 500 Tx de ilhotas foram realizados em centros de todo o mundo utilizando o protocolo de Edmonton ou versões modificadas desse procedimento.

Apesar do progresso no desenvolvimento do Tx de ilhotas, a necessidade de imunossupressão por toda a vida, a escassez e as dificuldades de acesso ao pâncreas de doadores falecidos, as dificuldades técnicas e o custo do isolamento das ilhotas, além da pouca durabilidade da insulinoindependência, representam obstáculos que restringem a sua utilização a pequeno grupo de pacientes cujo diabetes é marcado pela hiperlabilidade. Para estes pacientes o Tx de ilhotas tem mostrado ser uma intervenção benéfica que apresenta morbidade 20 vezes menor que o transplante de pâncreas, dado que é procedimento muito menos invasivo do ponto de vista cirúrgico (4).

\section{O PROCEDIMENTO DO TRANSPLANTE DE ILHOTAS}

As ilhotas são implantadas no fígado por meio de uma infusão na veia porta (esquema do procedimento na Figura 1). O acesso ao sistema venoso portal se faz através de cateterização transcutânea dirigida por ultra-sonografia; este método tem sido preferido em vez da cateterização de veia mesentérica realizada por microlaparotomia (Figura 2). As ilhotas acondicionadas em uma bolsa estéril siliconizada estão suspensas em aproximadamente $250 \mathrm{~mL}$ de meio

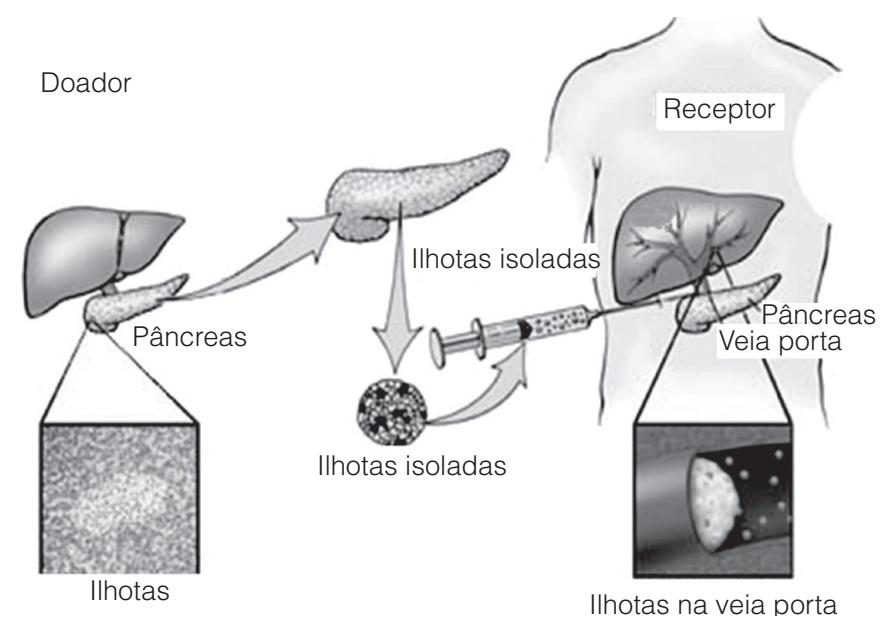

Figura 1. Esquema geral do procedimento (Adaptado de U. de Minnesota). 


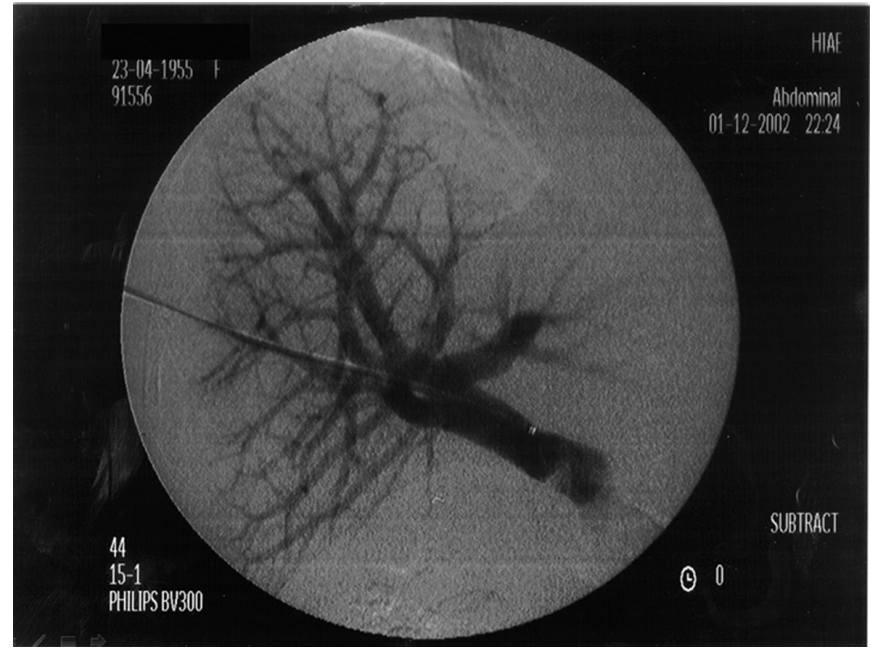

Figura 2. Confirmação da localização do cateter por portografia.

de cultura de células modificado (meio de transplante) contendo heparina (Figura 3). A infusão leva de 20 a 40 minutos para ser completada. Durante este período a pressão venosa portal é monitorizada e o procedimento deve ser interrompido se a pressão portal ultrapassar $20 \mathrm{~mm}$ de água ou atingir o dobro do valor basal. A escolha do figado como local do implante é decorrente da capacidade elástica deste órgão em acomodar o volume da infusão, do fato que a insulina ser fisiologicamente secretada no sangue portal e do sucesso clínico alcançado com este sítio de implante (5-7).

O sítio pancreático original é menos acessível cirurgicamente e as tentativas de infundir as ilhotas na veia esplênica foram acompanhadas de maior morbidade. No entanto, deve-se considerar que o fígado apresenta limitações importantes em relação à disponibilidade de oxi-

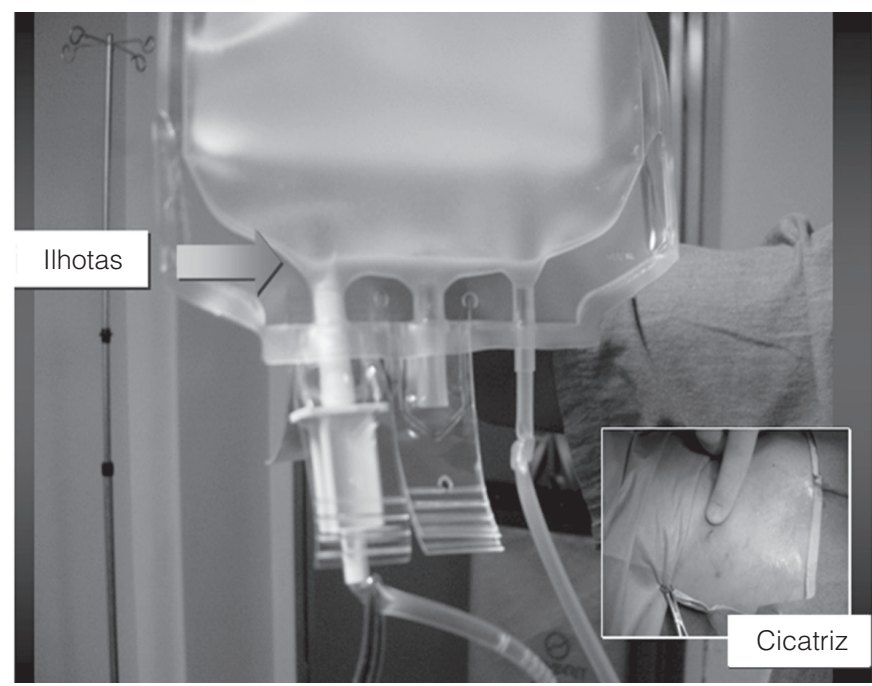

Figura 3. Ilhotas na bolsa de infusão. gênio, uma vez que a pressão parcial de $\mathrm{O}_{2}\left(\mathrm{PO}_{2}\right)$ nas pequenas veias portais varia de 8 a $10 \mathrm{mmHg}$ enquanto no pâncreas a $\mathrm{PO}_{2}$ é de $40 \mathrm{mmHg}$. (8). Além disso, o fígado representa um ambiente celular marcado pela hiperglicemia, pela exposição às toxinas de origem intestinal e a elevadas concentrações dos imunossupressores nos períodos em que ocorre a sua absorção intestinal, amplificando o efeito tóxico sobre as ilhotas ali implantadas. Por tudo isso, ultimamente, tem-se questionado se outros locais de implante como a serosa duodenal não seriam mais adequados à sobrevivência das ilhotas (9).

Apesar de relativamente pouco invasivo, o procedimento do Tx de ilhotas pode causar eventos adversos, os mais frequentes estão relacionados na Tabela 1 . As alterações das transaminases são transitórias e denotam o processo inflamatório associado à presença das ilhotas no parênquima hepático antes do processo de nidação. O sangramento é um risco inerente à punção hepática e ocorre em menos de $5 \%$ das punções, enquanto a ocorrência de trombose de ramos da veia porta se tornou um evento raro após o abandono da seringa e a adoção da infusão lenta das ilhotas contidas em bolsa siliconizada.

Tabela 1. Eventos adversos sérios mais comuns no transplante de ilhotas, relacionados ao procedimento. Dados acumulados de 579 infusões em 292 pacientes reportados por 56 centros (10).

\begin{tabular}{lccc}
\hline & número & $\begin{array}{c}\text { \%/número de } \\
\text { infusões }\end{array}$ & $\begin{array}{c}\% / \text { número de } \\
\text { eventos }\end{array}$ \\
\hline $\begin{array}{l}\text { Alteração das provas } \\
\text { de função hepática }\end{array}$ & 52 & 8,9 & 50,0 \\
$\begin{array}{l}\text { Sangramento } \\
\text { intra-abdominal ou } \\
\text { peritoneal }\end{array}$ & 16 & 2,7 & 15,7 \\
$\begin{array}{l}\text { Trombose de ramos } \\
\text { da veia porta }\end{array}$ & 7 & 1,2 & 7,8 \\
\hline Dor abdominal & 3 & 0,5 & 2,9 \\
Anemia & 2 & 0,3 & 1,0 \\
\hline
\end{tabular}

\section{O ACOMPANHAMENTO CLÍNICO DO PACIENTE TRANSPLANTADO}

Após o implante, a terapia com insulina deve ser mantida (usualmente com dois terços da dose anterior) para evitar a hiperglicemia (jejum $\geq 110 \mathrm{mg} \%$ e pós-prandial de 2 horas $\geq 180 \mathrm{mg} \%$ ), que pode dessensibilizar as ilhotas em relação à secreção de insulina induzida por glicose e também prejudicar a nidação das ilhotas. Com a vascularização das ilhotas e o início da secreção de insulina, a dose necessita ser diminuída gradualmente até 
a suspensão total por período que varia de 2 a 11 meses nos casos em que a insulino-independência for atingida (11-13).

O melhor parâmetro para acompanhar a evolução é a dosagem do peptídeo C, que em geral é indetectável antes do implante, e que se correlaciona diretamente com a massa de células-beta que efetivamente conseguiu se implantar no fígado e inversamente com a necessidade de insulina. $\mathrm{O}$ peptídeo $\mathrm{C}$ pode superestimar a massa celular quando há resistência à insulina ou diminuição da função renal e subestimá-la quando sua concentração diminui devido ao uso da insulina exógena o que, por efeito de feedback, inibe a secreção endógena de insulina (4,15-16).

Testes funcionais como a secreção de insulina estimulada por arginina, o teste de tolerância à glicose oral ou endovenosa são realizados periodicamente. Como a resposta varia de acordo com o tempo decorrido desde o transplante, é importante que este tempo seja considerado para efeito comparativo. A resposta ao estímulo é verificável após um mês do implante, mas os centros transplantadores consideram a resposta como máxima aquela obtida após um ano. Do ponto de vista clínico, o controle das glicemias, da Alc, do peptídeo C, o registro dos eventos de hipoglicemia e da necessidade de insulina são suficientes para o acompanhamento (17-20).

\section{A IMUNOSSUPRESSÃO NO TRANSPLANTE DE ILHOTAS}

A imunossupressão recomendada pelo protocolo de Edmonton consiste em daclizumabe, sirolimo e tacrolimo, sem o uso de corticóides. O daclizumabe (anticorpo monoclonal anti-CD25) é administrado por via endovenosa na dose de $1 \mathrm{mg} / \mathrm{kg}$ no dia do implante e em mais 4 aplicações, a cada 2 semanas, após cada infusão. O sirolimo é dado por via oral, uma vez ao dia, na dose necessária para manter o nível sérico na faixa de 12 a 15 $\mathrm{ng} / \mathrm{mL}$, durante os primeiros 3 meses; posteriormente, a dose é ajustada para manter níveis entre 7 a 12 ng/ $\mathrm{mL}$. A dose inicial administrada de sirolimo é de 0,2 $\mathrm{mg} / \mathrm{kg}$, a dose subseqüente é de $0,1 \mathrm{mg} / \mathrm{kg}$, que será depois ajustada semanal ou quinzenalmente até que as concentrações séricas desejadas sejam atingidas. $\mathrm{O}$ tacrolimo é administrado na dose inicial de 1 a $2 \mathrm{mg} /$ dia, depois é ajustada para manter a concentração sérica de 3 a 6 ng/mL. A terapia imunossupressora é mantida por toda a vida. Desse modo, é importante considerar os efeitos colaterais dos imunossupressores. A Tabela 2 relaciona os efeitos colaterais mais freqüentes da terapia imunossupressora.
Tabela 2. Efeitos adversos sérios mais comuns nos transplantes de ilhotas relacionados aos imunossupressores (10).

\begin{tabular}{|c|c|c|c|}
\hline \multicolumn{2}{|c|}{ Frequência maior que $3 \%$} & \multicolumn{2}{|c|}{ Frequência menor que $3 \%$} \\
\hline Neutropenia & 35,0 & Elevação da & \\
\hline Linfopenia & 7,8 & Infecções & \\
\hline Leucopenia & 4,7 & Herpes simp & \\
\hline Anemia & 3,1 & Úlceras de $\mathrm{m}$ & \\
\hline Vômito & 3,1 & Febre & \\
\hline Diarréia & 3,1 & Penumonia & 29 \\
\hline
\end{tabular}

Além dos eventos adversos relacionados à imunossupressão utilizada no protocolo de Edmonton devemos considerar o achado recente do seu efeito antiproliferativo e diabetogêni$\mathrm{co}$, tanto por seu efeito inibidor da secreção de insulina quanto por induzir resistência à ação deste hormônio $(6,11,21)$.

A associação do sirolimo com o tacrolimo frequentemente se agrega à linfocitopenia, o que desencadeia resposta homeostática proliferativa de linfócitos de memória, potencialmente capazes de recrudescer a resposta autoimune dirigida contra as ilhotas. Por esse motivo vários protocolos de imunossupressão alternativos estão atualmente em ensaio clínico (22).

\section{RESULTADOS DO TRANSPLANTE DE ILHOTAS}

Decorridos sete anos da publicação de J. Lakey e cols. (protocolo de Edmonton), o Tx de ilhotas seguindo este protocolo ou suas variantes, foi realizado em mais de 500 pacientes de 53 centros, incluindo o Núcleo de Terapia Celular e Molecular (Nucel), permitindo uma reavaliação crítica dos progressos e dos desafios que o Tx de ilhotas pancreáticas humanas ainda deve superar para migrar do campo da pesquisa clínica para o da terapia estabelecida.

A taxa de sucesso, medida pela insulino-independência em um ano, obtida nos três centros com maior experiência na América do Norte (Edmonton, Miami e Minneápolis) com a infusão de ilhotas obtidas de 1 a 4 pâncreas é de $82 \%$ (nos demais centros varia de $0 \%$ a $63 \%$ ) e em todos se observa perda progressiva da insulino-independência. Três anos após o transplante, $50 \%$ dos pacientes permanecem livres de insulina e após cinco anos, apenas 13\% dos pacientes não necessitam de insulina para controlar a sua glicemia. No entanto, o peptídeo C continua detectável em $80 \%$ dos pacientes e esta secreção residual da insulina traz o benefício da melhora ou o desaparecimento da labilidade (Figura 4), uma grande redução dos eventos hipoglicêmicos e da 
A

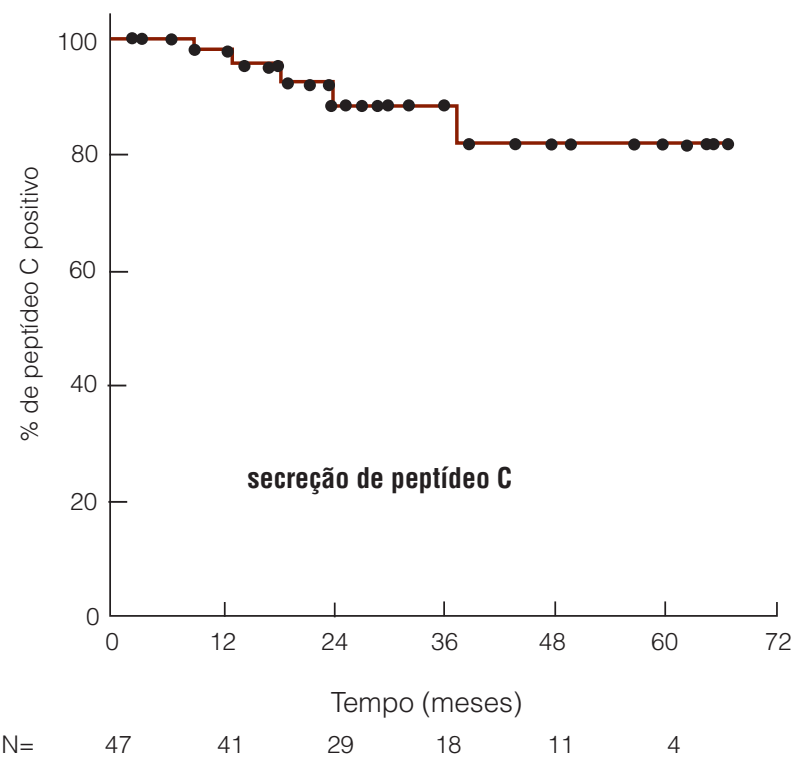

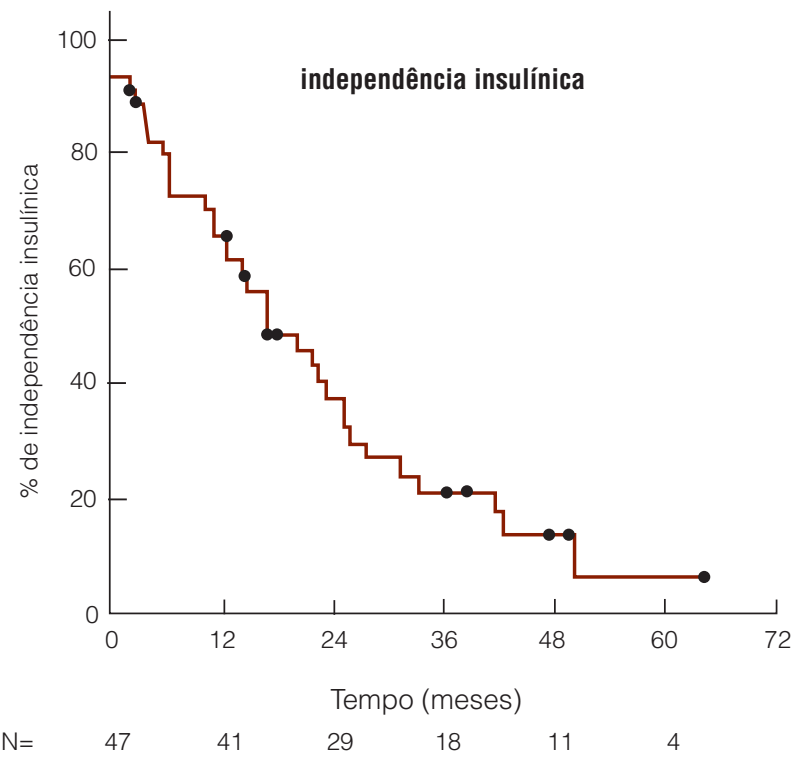

Figura 4. Secreção de peptídeo $\mathrm{C}$ e taxa de insulino-independência após 5 anos de acompanhamento pós-transplante de ilhotas (4).

manutenção de uma Alc dentro das metas recomendadas $(4,10,23-25)$.

Estes resultados mostram que o Tx de ilhotas, da forma como é realizado hoje, não deve ser considerado, para a maioria dos pacientes, como um método capaz de reverter o diabetes. No entanto, mesmo necessitando de insulina, a resolução das condições que levaram à indicação do Tx de ilhotas também pode ser considerada uma forma de sucesso.

Ryan e cols. (26) quantificaram os resultados medindo a evolução dos parâmetros HYPO e LI e desenvolveram uma medida da função das ilhotas transplantadas na forma de um beta-escore. Este é um índice que leva em consideração a glicemia de jejum, a necessidade de insulina, a hemoglobina glicada e a capacidade de produzir insulina quantificada pelo peptídeo C. O escore máximo de 8 significa a reversão completa do quadro de diabetes com insulino-independência, o escore mínimo de zero significa a falência total do enxerto (Tabela 3 ).

Tabela 3. Cálculo do beta-escore para avaliação da eficácia terapêutica do transplante de ilhotas.

\begin{tabular}{lccc}
\hline Componentes & Escore 2 & Escore 1 & Escore 0 \\
\hline GJ (mg/dL) & $\leq 99$ & $100-125$ & $\geq 126$ \\
HbA1c \% & $\leq 6,0$ & $6,2-6,9$ & $\geq 7,0$ \\
Insulina (U/kg) ou ADO & - & $0,01-0,24 /$ uso ADO & $\geq 0,25$ \\
Pep C - pós-estimulo (nmol/L & $\geq 0,3$ & $0,1-0,29$ & $\geq 0,1$ \\
\hline
\end{tabular}

Adaptado de Ryan e cols. (63)

\section{EFEITOS NO LONGO PRAZO DO TRANSPLANTE DE ILHOTAS}

$\mathrm{O}$ efeito protetor do Tx de ilhotas em relação às complicações microvasculares resta ser demonstrado; em relação às macrovasculares, o estudo retrospectivo de Fiorina e cols. revela melhora da função endotelial e cardiovascular em pacientes que receberam também um transplante renal $(11,27)$.

O seguimento no longo prazo de pacientes submetidos ao Tx de ilhotas permitiu que se identificassem efeitos colaterais que ocorrem mais tardiamente, como o desenvolvimento de focos de esteatose hepática, provavelmente decorrente do ambiente de hiperinsulinismo exacerbado em torno das áreas onde as ilhotas se implantaram. Embora sem grande expressão clínica detectada até o momento, a esteatose poderia ser um fator de lesão das ilhotas por lipoglucotoxicidade. A esteatose também ocorre em modelos experimentais e nestes é evitada por ação da leptina ou por restrição calórica (9).

Além disso, verificou-se o aparecimento de sensibilização contra antígenos HLA do doador, o que no caso de múltiplas infusões de diferentes doadores poderia levar a quadro de hipersensibilização capaz de dificultar a seleção de possível doador para outro transplante (renal). Por outro lado, tem-se notado que a tolerância da função renal em relação à ação nefrotóxica dos imunossupressores é menor em pacientes que tem clearance de creatinina prétransplante menor do que 70 ou $80 \mathrm{~mL} / \mathrm{min}$. Embora haja certa controvérsia dado o fato de que seja difícil excluir a 
progressão da nefropatia diabética em pacientes que de início já apresentavam declínio da função renal, a prudência impõe que sejam selecionados pacientes com função renal normal e, portanto com uma probabilidade menor de evolui para insuficiência renal, terminal quando forem submetidos à imunossupressão (28).

\section{MECANISMOS DE PERDA DA MASSA CELULAR IMPLANTADA}

Embora a rejeição e a recorrência da autoimunidade possam, com o passar do tempo, causar a destruição das ilhotas implantadas, há evidências de que a maior parte das ilhotas é destruída no período imediato ao implante, por mecanismo decorrente da imunidade inata. Estima-se que de $50 \%$ a $70 \%$ das ilhotas infundidas são perdidas por apoptose "induzida por estresse" ou pela Instant Blood-Mediated Inflammatory Response (IBMIR). Este processo foi estudado em detalhe por Korsgren e cols. (29) que demonstraram que as ilhotas humanas produzem grande quantidade de fator tecidual que causa adesão e ativação das plaquetas, provocando a ativação das cascatas do complemento e da coagulação, e atraindo granulócitos e monócitos que infiltram e destroem as ilhotas. Esta reação também pode ser precipitada pela secreção de quimiocinas, como a proteína químio-atratora de monócitos l (MCP-1). Qualquer que seja o agente iniciador da reação, a lesão das ilhotas, inevitavelmente, provoca a liberação de antígenos insulares que podem reativar a resposta imune específica, resultando no aumento ou no reaparecimento de autoanticorpos como o anti-GAD (29-37).

Além disso, há a perda, ao longo do tempo, da massa celular transplantada, uma vez que a taxa de regeneração das ilhotas implantadas no fígado é muito pequena ou inexistente. Há evidências de que no pâncreas normal formamse cerca de 250 mil ilhotas/ano e que esta reposição seria necessária para sustentar a tolerância à glicose normal ao longo da vida adulta. Dados experimentais mostraram que primatas submetidos à autotransplante de ilhotas por infusão portal, que se tornaram insulino-independentes, perderam essa condição quando ganharam massa corpórea pelo crescimento, demonstrando a incapacidade de multiplicação adaptativa das ilhotas implantadas no fígado (29-37).

Certamente, outros fatores como a atividade antiproliferativa dos imunossupressores, a autoimunidade, a rejeição crônica e o ambiente hepático podem ser também em parte responsáveis pela perda da insulino-independência, não obstante o grande número de ilhotas implantadas (mais de 12 mil equivalentes de ilhotas [IEQ] $/ \mathrm{kg}$ de peso do receptor).
Infelizmente, a nossa capacidade de detectar a rejeição das ilhotas é limitada. Os pacientes são monitorados por meio dos níveis de peptídeo $\mathrm{C}$, da dose de insulina necessária e da glicemia. Todos estes parâmetros podem permanecer inalterados em uma fase precoce do processo de rejeição que, eventualmente, poderia ser contido por um ajuste da terapia imunossupressora se detectado a tempo $(38,39)$. A dosagem do antígeno GAD65 não se revelou superior ao teste de tolerância à glicose simplificado. Tampouco há um método de imagem disponível que possa ser utilizado rotineiramente. Exames de imagem como a ressonância nuclear magnética usando lantanídeos, magnésio ou nanopartículas superparamagnéticas de óxido de ferro, estão em desenvolvimento, assim como exames de tomografia de emissão de prótons (PET) utilizando anticorpos específicos contra antígenos da célula-beta ou análogos do gliburide (39-40).

Os métodos histológicos (biópsias), ao contrário do que ocorre com os transplantes de órgãos sólidos não são habitualmente utilizados em razão da dificuldade de se obter uma amostra representativa contendo ilhotas por meio de biópsia hepática por punção $(38,39)$.

\section{PERSPECTIVAS FUTURAS DO TRANSPLANTE DE ILHOTAS}

O Tx de ilhotas foi aprovado como tratamento no Canadá e está em fase de aprovação pelo Foods and Drugs Administration (FDA), nos Estados Unidos. Mesmo que se aperfeiçoem os métodos de isolamento e se mantenham estritamente os critérios de inclusão, ainda assim haverá enorme discrepância entre a demanda e a oferta de pâncreas. O futuro de qualquer modalidade de terapia de reposição celular para o diabetes dependerá da criação de uma fonte sustentável de tecido secretor de insulina. Enquanto isso não ocorre, a estratégia é aperfeiçoar o procedimento, tentando-se obter a insulino-independência utilizando pâncreas de um único doador. Hering e cols. reportaram ter obtido a insulino-independência em oito pacientes que receberam uma única infusão contendo $7.271 \mathrm{IEQs} / \mathrm{kg}$, em média, e que destes, cinco pacientes se mantinham livres de insulina mais de um ano após o transplante. As técnicas aprimoradas de isolamento, o uso de antioxidantes e uma variante do protocolo de imunossupressão são os fatores aos quais os autores atribuíram este bom resultado $(11,41,42)$.

Outra estratégia que está sendo explorada é o transplante com doador vivo. Embora a reserva de células-beta e a capacidade regenerativa do pâncreas não sejam bem 
conhecidas, sabe-se que pacientes que se submetem à hemipancreatectomia distal são capazes de manter homeostase da glicose normal após a cirurgia. Alguns centros têm se utilizado de doadores vivos para realizar transplante de tecido pancreático apesar do risco de diabetes e de complicações cirúrgicas no doador. Do mesmo modo, estes doadores poderiam ser utilizados para o Tx de ilhotas. A primeira tentativa de realizar este procedimento foi feita por Sutherland e cols. 25 anos antes da introdução do método semi-automático de isolamento. Em 2005, este procedimento foi realizado com sucesso pela primeira vez, em Kyoto, quando um paciente portador de pancreatite crônica recebeu 408.144 IEQs isolados de segmento pancreático proveniente de um doador vivo relacionado, atingindo a insulino-independência 22 dias depois (43-44).

Ao lado de estratégias que aumentem a oferta de ilhotas, é necessário melhorar a eficácia e a tolerância dos imunossupressores. As modificações do protocolo de Edmonton que já estão sendo testadas em ensaios clínicos são: agentes que depletam linfócitos $\mathrm{T}$ como o alemtuzumabe, um anticorpo monoclonal anti-CD52 que bloqueia a ativação dos linfócitos $\mathrm{T}$ via a molécula $\mathrm{CD} 45$, e o anti-CD3 humanizado hOKT381 (ALA-ALA) que foi utilizado com sucesso no protocolo de doador único da Universidade de Minnesota, por Hering e cols. Agentes bloqueadores dos receptores co-estimuladores dos linfócitos $\mathrm{T}$, como o CTLA4 e o LEA29Y (belatacepte), que se ligam aos receptores CD80 e CD86 bloqueando a sua interação com o receptor co-estimulador CD28 e modulando a resposta imune (45-47).

Uma abordagem alternativa é inibir a migração dos linfócitos do sítio de ativação até o local onde irão agir. Esta migração depende da ação de quimiocinas, e agentes que inibem o trânsito dos linfócitos têm sido usados de modo crescente como agentes imunomoduladores. $\mathrm{O}$ FTY 720 é um inibidor inespecífico da migração dos linfócitos a partir do timo e dos gânglios, e tem sido usado em associação com o basiliximabe e o everolimo em modelos pré-clínicos de Tx de ilhotas. Além disso, vários ensaios têm buscado induzir a imunotolerância pela adição de tecido imunocompetente do doador para induzir o microquimerismo (48-53).

Paralelamente ao crescimento exponencial das alternativas de imunossupressão e de indução da imunotolerância, surgem as estratégias de imunoisolamento que buscam colocar as ilhotas em compartimentos a salvo do alcance das células imunocompetentes do receptor. Há ensaios em curso com macroencapsulamento e implante das ilhotas no tecido subcutâneo e ensaios pré-clínicos com ilhotas implantadas em microcápsulas. Além da padronização dos materiais utilizados e do uso em animais de médio/grande porte, as questões conceituais que necessitam ser esclarecidas se referem à longevidade e à duração das ilhotas encapsuladas, à permeabilidade ao oxigênio e aos mediadores inflamatórios e a resposta imune no longo prazo em relação ao material das cápsulas (54-56).

Mesmo que todas as questões relativas à imunossupressão venham a ser resolvidas, a demanda potencial por este procedimento não pode ser satisfeita apenas por ilhotas obtidas a partir de órgãos doados. O xenotransplante não está no horizonte clínico previsível para os próximos dez anos, em razão dos problemas ainda não resolvidos da rejeição hiperaguda, da presença de genomas virais, além das questões éticas envolvidas (57). Células-tronco ou progenitoras capazes de se diferenciar em células-beta potencialmente podem fornecer uma fonte ilimitada de células para a terapia de reposição. Há relatos iniciais da obtenção de células produtoras de insulina, a partir de células-tronco embrionárias, bem como a descrição de células multipotentes obtidas de ilhotas que in vitro se diferenciaram em células exócrinas, endócrinas e hepatócitas. Outra fonte potencial são as células multipotentes originárias da medula óssea, capazes de se diferenciar em hepatócitos que pertencem à mesma linhagem endodérmica que as células endócrinas das ilhotas (58-60).

\section{CONCLUSÕES}

O Tx de ilhotas representa a fronteira na inovação tecnológica para o tratamento de um grupo específico de pacientes portadores de DMl. É um procedimento terapêutico aprovado no Canadá, em fase de aprovação nos Estados Unidos e experimental nos demais países, incluindo o Brasil. Atualmente, este procedimento não deve ser encarado como modo seguro de atingir a insulinoindependência, porque, após cinco anos de seguimento, apenas pequena parcela dos pacientes se mantém livre de insulina, embora a grande maioria dos pacientes se beneficie do desaparecimento da hiperlabilidade. Com o desenvolvimento de novas técnicas de preparação das ilhotas e da imunossupressão dos pacientes, será possível atingir a insulino-independência com a infusão de massa celular menor e o Tx de ilhotas poderá oferecer a mesma eficácia clínica que o transplante de pâncreas, se não com menor custo com menor morbidade. Assim como o sucesso do transplante de pâncreas criou a motivação e a oportunidade para que o Tx de ilhotas se desenvolvesse, esta nova modalidade criará a oportunidade e a motivação para o desenvolvimento do transplante, utilizando células provenientes de fontes alternativas como as cé- 
lulas-tronco diferenciadas no laboratório, e estimulará o desenvolvimento de técnicas de indução da imunotolerância e de imunoisolamento, porque este é o caminho para tornar a terapia de reposição celular aplicável a uma população maior de pacientes $(11,54,61,62)$.

Declaração: Dr. Freddy Goldberg Eliaschewitz participa do Adviser Board das indústrias Sanofi-Aventis, Lilly e Johnson \& Johnson. Não houve qualquer influência destas empresas na redação deste texto. Os outros autores não possuem conflitos de interesse.

\section{REFERÊNCIAS}

1. Merani S, Shapiro AM. Current status of pancreatic islet transplantation. Clin Sci (Lond). 2006;110:611-25.

2. The Diabetes Control and Complications Trial Research Group: the effect of intensive treatment of diabetes on development and progression of long-term complications in insulin-dependent diabetes mellitus. N Engl J Med. 1993;329:977-86.

3. Shapiro AM, Lakey JR, Ryan EA, Korbutt GS, Toth E, Warnock GL, et al. Islet transplantation in seven patients with type 1 diabetes mellitus using a glucocorticoid-free immunosuppressive regimen. $\mathrm{N}$ Engl J Med. 2000;343:230-8.

4. Ryan EA, Paty BW, Senior PA, Bigam D, Alfadhli E, Kneteman NM, et al. Five-year follow-up after clinical islet transplantation. Diabetes. 2005;54:2060-9.

5. Eliaschewitz FG, Aita CA, Genzini T, Noronha IL, Lojudice FH, Labriola $L$, et al. First Brazilian pancreatic islet transplantation in a patient with type 1 diabetes mellitus. Transplant Proc. 2004;36:1117-8.

6. Shapiro AM, Lakey JR, Rajotte RV, Warnock GL, Friedlich MS, Jewell LD, Kneteman NM. Portal vein thrombosis after transplantation of partially purified pancreatic islets in a combined human liver/islet allograft. Transplantation. 1995;59:1060-3.

7. Merani S, Shapiro AM. Current status of pancreatic islet transplantation. Clin Sci (Lond). 2006;110:611-25.

8. Pileggi A, Ricordi C, Alessiani M, Inverardi L. Factors influencing Islet of Langerhans graft function and monitoring. Clin Chim Acta. 2001;310:3-16.

9. Lee Y, Ravazzola M, Park BH, Bashmakov YK, Orci L, Unger RH. Metabolic mechanisms of failure of intraportally transplanted pancreatic beta-cells in rats: role of lipotoxicity and prevention by leptin. Diabetes. 2007;56:2295-301.

10. Collaborative Islet Transplantation Registry [acesso em 2007]. Disponível em: http:Ilspitfire.emmes.com/study/isl/index.html.

11. Tattersall RB. Brittle diabetes revisited: the Third Arnold Bloom Memorial Lecture. Diabet Med. 1997;14:99-110.

12. Dutour A, Boiteau V, Dadoun F, Feissel A, Atlan C, Oliver C. Hormonal response to stress in brittle diabetes. Psychoneuroendocrinology. 1996;21:525-43.

13. Biarnes M, Montolio M, Nacher V, Raurell M, Soler J, Montanya E. Beta-cell death and mass in syngeneically transplanted islets exposed to short- and long-term hyperglycemia. Diabetes. 2002;51:66-72.

14. Luzi L, Perseghin G, Brendel MD, Terruzzi I, Battezzati A, Eckhard M, et al. Metabolic effects of restoring partial beta-cell function after islet allotransplantation in type 1 diabetic patients. Diabetes. 2001;50:277-82.

15. Alejandro R, Lehmann R, Ricordi C, Kenyon NS, Angelico MC, Burke G, et al. Long-term function (6 years) of islet allografts in type 1 diabetes. Diabetes. 1997;46:1983-9.

16. Faradji RN, Monroy K, Cure P, Froud T, Baidal D, Pileggi A, et al. C-peptide and glucose values in the peritransplant period after intraportal islet infusions in type 1 diabetes. Transplant Proc. 2005;37:3433-4.
17. Rickels MR, Schutta MH, Markmann JF, Barker CF, Naji A, Teff KL. \{beta\}-Cell function following human islet transplantation for type 1 diabetes. Diabetes. 2005;54:100-6.

18. Bergman RN, Ader M, Huecking K, Van Citters G. Accurate assessment of beta-cell function: the hyperbolic correction. Diabetes. 2002;51 Suppl 1:S212-20.

19. Ryan EA, Lakey JR, Paty BW, Imes S, Korbutt GS, Kneteman NM, et al. Successful islet transplantation: continued insulin reserve provides long-term glycemic control. Diabetes. 2002;51:2148-57.

20. Teuscher AU, Kendall DM, Smets YF, Leone JP, Sutherland DE, Robertson RP. Successful islet autotransplantation in humans: functional insulin secretory reserve as an estimate of surviving islet cell mass. Diabetes. 1998;47:324-30.

21. Hering BJ, Kandaswamy R, Harmon JV, Ansite JD, Clemmings SM, Sakai T, et al. Transplantation of cultured islets from two-layer preserved pancreases in type 1 diabetes with anti-CD3 antibody. Am J Transplant. 2004;4:390-401.

22. Van Belle T, von Herrath M. Immunosuppression in islet transplantation. J Clin Invest. 2008 May;118(5):1625-8.

23. Froud T, Ricordi C, Baidal DA, Hafiz MM, Ponte G, Cure $P$, et al. Islet transplantation in type 1 diabetes mellitus using cultured islets and steroid-free immunosuppression: Miami experience. Am J Transplant. 2005;5:2037-46.

24. Kempf MC, Andres A, Morel P, Benhamou PY, Bayle F, Kessler L, et al. Logistics and transplant coordination activity in the GRAGIL SwissFrench multicenter network of islet transplantation. Transplantation. 2005;79:1200-5.

25. Shapiro AM, Ricordi C, Hering BJ, Auchincloss H, Lindblad R, Robertson $\mathrm{RP}$, et al. International trial of the Edmonton protocol for islet transplantation. N Engl J Med. 2006;355:1318-30.

26. Ryan EA, Paty BW, Senior PA, Lakey JR, Bigam D, Shapiro AM. Betascore: an assessment of beta-cell function after islet transplantation. Diabetes Care. 2005;28:343-7.

27. Fiorina P, Folli F, Bertuzzi F, Maffi P, Finzi G, Venturini M, et al. Longterm beneficial effect of islet transplantation on diabetic macro-/microangiopathy in type 1 diabetic kidney-transplanted patients. Diabetes Care. 2003;26:1129-36.

28. Maffi P, Bertuzzi F, De Taddeo F, Magistretti P, Nano R, Fiorina P, et al. Kidney function after islet transplant alone in type 1 diabetes: impact of immunosuppressive therapy on progression of diabetic nephropathy. Diabetes Care. 2007;30:1150-5.

29. Bennet W, Groth CG, Larsson R, Nilsson B, Korsgren O. Isolated human islets trigger an instant blood mediated inflammatory reaction: implications for intraportal islet transplantation as a treatment for patients with type 1 diabetes. Ups J Med Sci. 2000;105:125-33.

30. Moberg L, Johansson H, Lukinius A, Berne C, Foss A, Källen R, et al. Production of tissue factor by pancreatic islet cells as a trigger of detrimental thrombotic reactions in clinical islet transplantation. Lancet. 2002;360:2039-45.

31. Ozmen L, Ekdahl KN, Elgue G, Larsson R, Korsgren O, Nilsson B. Inhibition of thrombin abrogates the instant blood-mediated inflammatory reaction triggered by isolated human islets: possible application of the thrombin inhibitor melagatran in clinical islet transplantation. Diabetes. 2002;51:1779-84.

32. Korsgren O, Nilsson B, Berne C, Felldin M, Foss A, Kallen R, et al. Current status of clinical islet transplantation. Transplantation. 2005; 79:1289-93.

33. Moberg L, Korsgren O, Nilsson B. Neutrophilic granulocytes are the predominant cell type infiltrating pancreatic islets in contact with $A B O-$ compatible blood. Clin Exp Immunol. 2005;142:125-31.

34. Johansson $H$, Lukinius A, Moberg L, Lundgren T, Berne C, Foss A, et al. Tissue factor produced by the endocrine cells of the islets of Lan- 
gerhans is associated with a negative outcome of clinical islet transplantation. Diabetes. 2005;54:1755-62.

35. Goto M, Johansson H, Maeda A, Elgue G, Korsgren O, Nilsson B. Lowmolecular weight dextran sulfate abrogates the instant blood-mediated inflammatory reaction induced by adult porcine islets both in vitro and in vivo. Transplant Proc. 2004;36:1186-7.

36. Moberg L, Olsson A, Berne C, Felldin M, Foss A, Källen R, et al. Nicotinamide inhibits tissue factor expression in isolated human pancreatic islets: implications for clinical islet transplantation. Transplantation. 2003;76:1285-8.

37. Yang Z, Chen M, Ellett JD, Carter JD, Brayman KL, Nadler JL. Inflammatory blockade improves human pancreatic islet function and viability. Am J Transplant. 2005;5:475-83.

38. Shapiro AM, Hao E, Lakey JR, Elliott JF, Rajotte RV, Kneteman NM. Development of diagnostic markers for islet allograft rejection. Transplant Proc. 1998;30:647.

39. Shapiro AM, Hao EG, Lakey JR, Yakimets WJ, Churchill TA, Mitlianga PG, et al. Novel approaches toward early diagnosis of islet allograft rejection. Transplantation. 2001;71:1709-18.

40. Paty BW, Bonner-Weir S, Laughlin MR, McEwan AJ, Shapiro AM. Toward development of imaging modalities for islets after transplantation: insights from the National Institutes of Health Workshop on Beta Cell Imaging. Transplantation. 2004;77:1133-7.

41. Hering BJ, Kandaswamy R, Ansite JD, Eckman PM, Nakano M, Sawada $\mathrm{T}$, et al. Single-donor, marginal-dose islet transplantation in patients with type 1 diabetes. JAMA. 2005;293:830-5.

42. Smith CV. Single-donor islet transplantation for diabetes. JAMA. 2005;294:1488; author reply 1488-9.

43. Sutherland DE, Matas AJ, Goetz FC, Najarian JS. Transplantation of dispersed pancreatic islet tissue in humans: autografts and allografts. Diabetes. 1980;29 Suppl 1:31-44.

44. Matsumoto S, Okitsu T, Iwanaga Y, Noguchi H, Nagata H, Yonekawa $Y$, et al. Insulin independence after living-donor distal pancreatectomy and islet allotransplantation. Lancet. 2005;365:1642-4.

45. Calne R, Moffatt SD, Friend PJ, Jamieson NV, Bradley JA, Hale G, et al. Campath IH allows low-dose cyclosporine monotherapy in 31 cadaveric renal allograft recipients. Transplantation. 1999;68:1613-6.

46. Knechtle SJ, Pirsch JD, H. Fechner J Jr, Becker BN, Friedl A, Colvin RB, Lebeck LK, et al. Campath-1H induction plus rapamycin monotherapy for renal transplantation: results of a pilot study. Am J Transplant. 2003;3:722-30.

47. Rao V, Pirsch JD, Becker BN, Knechtle SJ. Sirolimus monotherapy following Campath-1H induction. Transplant Proc. 2003;35:128S-30.

48. Larsen CP, Pearson TC, Adams AB, Tso P, Shirasugi N, Strobertm E, et al. Rational development of LEA29Y (belatacept), a high-affinity variant of CTLA4-Ig with potent immunosuppressive properties. Am J Transplant. 2005;5:443-53.

49. Vincenti F, Larsen C, Durrbach A, Wekerle T, Nashan B, Blancho G, et al. Costimulation blockade with belatacept in renal transplantation. $\mathrm{N}$ Engl J Med. 2005;353:770-81.

50. Yopp AC, Fu S, Honig SM, Randolph GJ, Ding Y, Krieger NR, Bromberg JS. FTY720-enhanced T cell homing is dependent on CCR2, CCR5, CCR7, and CXCR4: evidence for distinct chemokine compartments. J Immunol. 2004;173:855-65.

51. Wijkstrom M, Kenyon NS, Kirchhof N, Kenyon NM, Mullon C, Lake P, et al. Islet allograft survival in nonhuman primates immunosuppressed with basiliximab, RAD, and FTY720. Transplantation. 2004;77:827-35.

52. Billingham RE, Brent L, Medawar PB. Actively acquired tolerance of foreign cells. Nature. 1953;172:603-6.

53. Sayegh MH, Fine NA, Smith JL, Rennke HG, Milford EL, Tilney NL. Immunologic tolerance to renal allografts after bone marrow transplants from the same donors. Ann Intern Med. 1991;114:954-5.

54. Nath DS, Hering BJ. Islet cells replacement therapy. Clin Lab Med. 2005;25:541-56.

55. Lim F, Sun AM. Microencapsulated islets as bioartificial endocrine pancreas. Science. 1980;210:908-10.

56. Duvivier-Kali VF, Omer A, Parent RJ, O'Neil JJ, Weir GC. Complete protection of islets against allorejection and autoimmunity by a simple barium-alginate membrane. Diabetes. 2001;50:1698-705.

57. van der Laan LJ, Lockey C, Griffeth BC, Frasier FS, Wilson CA, Onions $D E$, et al. Infection by porcine endogenous retrovirus after islet xenotransplantation in SCID mice. Nature. 2000;407:90-4.

58. Zulewski H, Abraham EJ, Gerlach MJ, Daniel PB, Moritz W, Müller B, et al. Multipotential nestin-positive stem cells isolated from adult pancreatic islets differentiate ex vivo into pancreatic endocrine, exocrine, and hepatic phenotypes. Diabetes. 2001;50:521-33.

59. Ramiya VK, Maraist M, Arfors KE, Schatz DA, Peck AB, Cornelius JG. Reversal of insulin-dependent diabetes using islets generated in vitro from pancreatic stem cells. Nat Med. 2000;6:278-82.

60. Schwartz RE, Reyes M, Koodie L, Jiang Y, Blackstad M, Lund T, et al. Multipotent adult progenitor cells from bone marrow differentiate into functional hepatocyte-like cells. J Clin Invest. 2002;109:1291-302.

61. Bertuzzi F, Ricordi C. Prediction of clinical outcome in islet allotransplantation. Diabetes Care. 2007;30:410-7.

62. de Sá JR, Gonzalez AM, Melaragno CS, Saitovich D, Franco DR, Rangel $E B$, et al. Transplante de pâncreas e ilhotas em portadores de diabetes melito. Arq Bras Endocrinol Metab, 2008;52:355-66.

63. Ryan EA, Shandro T, Green K, Paty BW, Senior PA, Bigam D, et al. Assessment of the severity of hypoglycemia and glycemic lability in type 1 diabetic subjects undergoing islet transplantation. Diabetes. 2004;53:955-62. 